\title{
Vocabulary Breadth and Field Dependence/Independence Cognitive Styles
}

\author{
Nassim Golaghaei \\ (Roudehen Branch, Islamic Azad University, Roudehen, Iran) \\ doi:10.7575/aiac.alls.v.2n.2p.156
}

\begin{abstract}
This article is primarily bidirectional in that it is concerned with two cognitive styles of fielddependency/independency on the one hand and breadth of vocabulary knowledge on the other hand. In other words, the present research primarily intends to investigate the nature of the students' vocabulary knowledge in the field of passive and active knowledge of L2 words as a whole with regard to their preferred cognitive style of field-dependency/independency. A group of 60 undergraduate students majoring in the field of English translation was selected. They were then divided into two groups on the basis of their preferred cognitive styles of field-dependency/independency. Four types of tests, the 1000 frequency Word-Level Test, the passive version of the Vocabulary Levels Test, the productive version of the Vocabulary Levels Test, and the Group Imbedded Figures Test were administered to the participants. The conclusion drawn after the analysis of the data was that the participants in the fieldindependent group outperformed their field-dependent counterparts regarding both passive and productive vocabulary levels. Finally, the findings of this piece of research could be interpreted as being supportive of the idea that the cognitive styles of fielddependency/independency could be considered as an effective factor influencing the learners' vocabulary learning.
\end{abstract}

\section{Introduction}

Among different components of language, vocabulary stands out as the most significant yet the most neglected one. One of the main reasons for English to be the lingua franca of today's world is that English possesses the most comprehensive stock of vocabulary among different languages of today. Only recently have researchers come to understand the relative importance of vocabulary acquisition in the field of language learning. Some of the recent investigations that shed light upon different aspects of vocabulary acquisition include Huckin, Haynes, and Coady (1993), Harley (1995), Hatch and Brown (1995), Coady and Huckin 
(1997), Schmitt and McCarthy (1997), Atkins (1998), Wesche and Paribakht (1999), Read (2000), Schmitt (2000), Nation (2001), and Wesche and Paribakht (2010). They all provide some discussions expatiating upon the importance of vocabulary learning and teaching.

However, in recent years there has been an increasing awareness of the necessity in second language research and teaching to examine cognitive aspects that have undeniable effects on language learning and teaching. It is worth mentioning that if we were to devise theories of second language acquisition and teaching methods which were only based on effective considerations, we would be omitting the most fundamental side of human cognition as cognitive considerations.

Therefore, the general idea of this research is bi-dimensional in the whole sense, in that it aims to provide a digest of recent research on the relationship between vocabulary acquisition and cognitive styles of field-dependency/independency and to pinpoint areas that need further exploration. It is argued that despite the impressive amount of recent research on vocabulary acquisition, a cognitive-based perspective that is presented here is needed to evaluate the existing research in a larger framework and to point to novel areas for further efforts.

\section{Review of the Related Literature}

Any investigation regarding vocabulary acquisition and lexical knowledge encompasses an understanding of the fundamental concepts of semantic, lexicon, lexical knowledge, and vocabulary. Evidently, such a scrutiny could be helpful in finding tools and procedures to measure vocabulary knowledge.

Hatch and Brown (1995) defined semantics as the investigation of meaning and the systematic ways those meanings are expressed in language. Accordingly, lexicon could be elucidated in terms of the overall system of word forms, and when we insert morphology, the study of word formation in languages.

Many researchers nowadays agree that rather than viewing lexical knowledge as an all or nothing phenomenon, investigators should construe lexical knowledge as a continuum consisting of several levels and dimensions of knowledge. One suggestion in line with the above-mentioned idea is cited by Laufer and Paribakht (1998). Accordingly, this continuum is viewed as initiating with "the 'word form' (knowing that the item is a word in the target 
language) and terminating with the ability to adopt the word appropriately in free communicative production'” (p. 337). However, Palmberg (1987) adopted a slightly different position regarding word knowledge. He believes that the potential vocabulary should be placed at the initial position of the continuum; that is, words that the learner has never been exposed to but can easily comprehend due to the fact that they are cognates in his or her first language. It is important to note that passive and active vocabulary occupies the other extreme of this continuum.

Another perspective regarding different types of words is provided by Shaw and Date (1986) who made a sharp distinction between different types of lexical items. They stated that each person owns three types of vocabularies: active speaking vocabulary, writing vocabulary, and potential or recognition vocabulary. By active vocabulary one can refer to those words that individuals use while they are involved in daily communicative situations in their speech. On the other hand, writing vocabulary can be defined as the words we use while writing. Some of the words of this domain are not employed in our speech. In addition to these two types of active vocabularies, they coined the term 'recognition vocabulary' which encompasses the largest area. Potential or recognition vocabulary includes those words that we recognize and interpret mainly because of the existence of some contextual clues but which we would not be able to use in our speaking or writing activities. These words are not considered to be really ours until we attempt to manipulate the words and make them work for us. Therefore, we have to make a steady effort to move the words from our potential to our active vocabulary which is considered to be the initial step in vocabulary improvement.

Laufer and Paribakht (1998) viewed vocabulary knowledge from another perspective by stating that:

The relationship between an L2 learner's passive and active vocabularies remains interesting but unexplored; statements about this relationship have been vague and unsubstantiated. Most writers have assumed that passive vocabulary is larger than active (e.g., Aitchison, 1989; Channel, 1988). However, no one has conclusively demonstrated how much larger it is, or whether growth in passive vocabulary automatically results in growth in active vocabulary, or whether the gap between the two remains stable or changes over time. (p.369)

There are several methods of assessing vocabulary size with regard to active and passive word knowledge. Among the most prominent ones, the Vocabulary Levels Test (VLT) was proposed by Nation as a measure of learners' breadth of lexical knowledge in 1983 and its revised version in 1990. As Schmitt et al. (2000) mentioned, the VLT "provides 
a profile of a learner's vocabulary, rather than a single figure estimate of overall vocabulary size" (p. 58).

In VLT, five levels were selected for testing vocabulary as the $2^{\text {nd }} 1000$ word level, the $3^{\text {rd }}$ 1000 word level, the $5^{\text {th }} 1000$ word level, the academic word level, and the $10^{\text {th }} 1000$ word level. A representative sample of 60 words was taken from each of the five levels. The 60 words at each level were grouped into blocks of six words on the basis of the part of speech. The words in each block were then checked to make sure that they were not similar in form or related meaning. In this way the distracters in each block were not distracting (Schmitt, Schmitt \& Clapham, 2001). Such a case will assist the learners with partial knowledge of a lexical item to select the correct answer. It is important to note that the aim of VLT is to get an accurate record of what the learners know even of the words that they have not yet fully learned. Three words in each block of six were randomly chosen as the words to be tested. However, the other three in the block were the distracters. The tests were checked for reliability and validity by Schmitt, Schmitt and Clapham (2001).

Now that we have a crystallized perspective regarding the importance of vocabulary acquisition, the concept of vocabulary, different kinds of vocabulary with respect to passive and productive one as well as the most prominent method of measuring vocabulary breadth, it is time to embark upon gliding towards the second cornerstone of this research project as field-dependency/independency cognitive styles and to justify their relative significance regarding the passive and productive lexical knowledge as the first zone of the present study.

We are well aware that we harbor preferences with regard to what we are interested in learning and how we wish to learn. Moreover, we prefer and process information in distinctively personal ways. Some of us prefer to work alone; others enjoy group experiences. Some have a better performance when they become exposed to the information visually.

For years, psychologists and educators have tried to better understand, describe, and measure individual learning preferences and styles. As a consequence, many different points of view have emerged and a number of terms have been coined to explicate these styles (Della-Dora \& Blanchard, 1979 cited in Cruickshank, Jenkins \& Metcalf, 2006). For instance, our learning 
style can be thought of as our 'learning personality'. It is a consistent pattern of behavior and performance we use to approach learning experiences.

The most familiar way of measuring and describing a person's learning style is related to the process of exploring his/her cognitive style. Dembo (2000) defined cognitive style as the consistent techniques to which a person resorts in the way of reacting to a wide range of perceptual tasks. In the same way cognitive styles are regarded as "broad stylistic behavioral characteristics that cut across abilities and personality and are manifested in many activities and media" (Anastasi \& Urbina, 2005, p. 236).

The most controversial styles in the literature are field-dependence and field-independence. The cognitive style of field-sensitive versus field-independent was initially explicated by Witkin et al. (1962, 1981). Students differ along this continuum, which is part of every one's cognitive style. On the one hand, are students, who view situations in their totality, seeing a whole pattern or gestalt. They see the forest as opposed to seeing individual trees there in. Such learners are called field-sensitive. Field-dependent or the field-sensitive students tend to be more gregarious or people-oriented. In other words, in interpersonal situations they tend to have certain advantages compared with their field-independent counterparts in getting along with others. As mentioned by Anastasi and Urbina (2005), they tend to be attentive to social cues. Therefore, as cited by Cruickshank, Jenkins, and Metcalf (2006), they are better at learning material with the social content such as social studies, social sciences, and literature. One of the prominent features of this group is that they have difficulty noticing or picking out details and working with materials presented to them in an unstructured way. For instance, as mentioned by Witkin et al. (1981), field-sensitive learners may have difficulty with math word problems because they do not identify and distinguish between relevant and irrelevant information. Furthermore, these learners are more responsive to praise and other kinds of reinforcement and they are more adversely affected by criticism.

On the other hand, the field-independent learners focus more easily on the trees or the details. Curiosity, self-reliance, less conformity, and obedience are among the major properties of this group. As stated by Witkin et al. (1981), they are more inclined towards task-oriented activities, and they work better with unstructured tasks such as problem-solving activities. On the downside, perhaps, field-independent learners have more difficulty learning social content 
and working with others. Compared with their field-sensitive counterparts, they are less affected by the teacher's appraisal or criticism.

Group Imbedded Figures Test (GEFT) is considered as a measure of field independence in a purely visual, paper-and-pencil situation. The major technique in the usual test for measuring the cognitive style of field-independence/dependence (GEFT) is related to the ability to distinguish hidden figures in a complicated picture.

FI subjects score high in GEFT. The reason is inherent in the distinction made by Chapelle and Roberts (1986) between field-dependent/independent individuals. They asserted that a field-independent person, due to his/her cognitive characteristics is prone to approach a problem solving activity analytically, while a field-dependent person may embark upon fulfilling this task in a global way. In a problem solving field, a highly field-independent person is well-equipped with the ability to detect patterns and sub-patterns, while a fielddependent person cannot escape from the predicament of the complexity of the context and tends to get lost in the totality of the stimuli. Srivastava (1997) believes that "since GEFT is a group test, a comparative view is revealed. There is no cutting point that indicates the individual's own cognitive style whether he is FD or FI" (p.16).

As mentioned by Anastasi and Urbina (2005), there is evidence that the cognitive style of field-dependence/independence exhibits considerable stability through childhood and early adulthood and is related to a number of personality variables, such as leadership (Weissenberg \& Gruenfeld, 1966), social conformity (Witkin et al., 1974), and many others (Jonassen \& Grabowski, 1993). Furthermore, Anastasi and Urbina (2005) refer to the diversity of research related to field-dependence which are truly impressive, ranging from interpersonal relations (Witkin \& Goodenough, 1977) to learning and memory (Goodenough, 1976), mathematics achievement (Vaidya \& Chanski, 1980), cross-cultural differences (Berry, 1976), and work environment preferences (Wooten, Barner \& Silver, 1994).

As mentioned by Witkin and Goodenough (1981), and Witkin (1962, as cited in Brown, 2007), as a child matures to adulthood, field independency increases and the person tends to be dominant in one mode or the other. Furthermore, it is emphasized that fieldindependence/dependence (FID) is in one sense culture-bound and gender-based. For instance, males in western culture have been found to be more FI. Cross-culturally, the 
society which nurtures the child is decisive in the extent of the development of (FID) as the child matures into adulthood. As mentioned by Brown (2007), "authoritarian or agrarian societies, which are usually highly socialized and utilized strict rearing practices, tend to produce more FDs. A democratic, industrialized, competitive society with freer rearing norms tends to produce more FI persons" (p.121).

According to Dulay, Burt, and Krashen (1982, as cited in Adamopoulos, 2004) more analytical, field independent characteristics appear to be relevant to the acquisition of metalinguistic skills through conscious learning. However, the field dependent individual seems to be more prone to learn communication skills through the process of subconscious learning.

An example of the intriguing relationships that emerge from the results of many studies is the finding that field-independent persons tend to follow active, "participant" approaches to learning. However, field-dependent persons more often use "spectator" approaches. Several studies have been carried out investigating the relationship between this cognitive style and success in different fields of language learning. As mentioned by d' Anglejan and Renaud (1985, cited in Williams \& Burden, 1997), some of these studies presented a somewhat meaningful correlation between high field-independency and greater achievement in learning a foreign language.

Lu and Suen (1995, as cited in Cruickshan, Jenkins \& Metcalf, 2006) compared the outcomes of Multiple-choice tests and Performance-based assessments. The results of the study suggest that field-independent learners could perform better dealing with performance-based assessments which demand greater active participation on the part of the learner. In addition, the results of the research carried out by Yamini and Rahnama (2008) indicated that fieldindependent students perform much better in reading comprehension compared with their field-dependent counterparts. However, on the logical side it appears that neither end of the field-dependent/independent continuum is necessarily or uniformly favorable or unfavorable; rather, the value of deviations in either direction primarily depends on the demands of particular situations. Therefore, familiarity with various cognitive style differences would be beneficial to teachers to evaluate the learners' knowledge of language in different fields considering these undeniable differences and ultimately plan and execute their instructional activities in a more flexible and responsive manner. However, the major concern of this piece 
of research is to evaluate the learners' passive versus productive vocabulary knowledge considering their preferred cognitive styles (field-dependency/independency).

\section{Research Questions}

The present study set out to seek answers to the following questions:

1. Is there any significant difference between field-dependents and field-independents in their passive knowledge of vocabulary?

2. Is there any significant difference between field-dependents and field-independents in their active knowledge of vocabulary?

\section{Method}

\section{Participants}

The participants comprised 80 juniors majoring in English translation, studying at the Islamic Azad University, Roudehen Branch. Initially, they were all given the 2000 word frequency to make sure that they were capable of attending levels with less frequent words at the time of testing administration. Nine cases were omitted at the beginning of the study since they were measured as low-level ability subjects on the basis of their performance on 2000 word frequency level. The productive and passive frequency Levels Tests were administered in two separate sessions with 4 weeks interval to minimize the probable test effect. Finally, the students were provided with the Group Imbedded Figures Test as a measure of fielddependency/independency. Eleven of the subjects were excluded from the study due to the fact that they were not present in both sessions of test administrations. The final data was analyzed with reference to the 60 remaining subjects in the end.

\section{Instruments}

It is worth mentioning that four types of tests were administered in the present study including the 1000 Vocabulary Level Test, the Vocabulary Levels Test (version 1), the productive version of the Vocabulary Levels Test, and the Group Imbedded Figures Test (GEFT).

The 1000 Vocabulary Level Test

The 1000 Word Level Test developed by Nation (1993) consists of 40 items. Each item is in the form of a full sentence accompanied by a picture. The students are expected to write $\mathrm{T}$ 
if a sentence is true, $\mathrm{N}$ if it is not true and $\mathrm{X}$ if they do not understand the sentence. Only content words (nouns, verbs, adjectives, and adverbs) are tested.

Passive Vocabulary Levels Test (Version 1)

The Vocabulary Levels Test (VLT) was used to measure students' comprehension of the most basic and frequent meanings of the target words. It encompasses samples from five levels of frequency which are as follows: the 2000 most frequent words, the 3000 most frequent words, the fifth thousand, the University Word list (Xue \& Nation, 1984) and the tenth thousand most frequent words. Learners are expected to match groups of three words out of six with their paraphrases as follows: 1.

birth

2. dust game

3. operation

4. row winning

5. sport

6. victory being born

It is worthwhile to mention that the major purpose of this test is to measure the learners' sight vocabulary; that is, the number of words they understand without any contextual clues. The test consists of five separate sections allocated to each of the five frequency levels. Each section includes 18 items which gives the maximum score of 90 on the whole test package. Dichotomous scores are assigned to the answers with one point to each correct answer and zero to incorrect or blank ones.

Productive Version of the Vocabulary Levels Test

This test was developed by Laufer and Nation (1999) with the purpose of measuring the learners' productive vocabulary size. The major difference between this test and the VLT is that items are not provided but rather elicited in short sentences. However, the first letter of the target word is provided to avoid the elicitation of non-target words which may fit the sentence context. For instance, "She earns a high sal... as a lawyer."

Like the previously mentioned test, VLT, this test also consists of five frequency levels, each comprising 18 items, with a maximum score of 90.The items were scored dichotomously in that each correct response receives one point and each incorrect or blank one receives zero. 
Furthermore, items with incorrect grammatical form (e.g. present instead of past) or unobtrusive errors are marked as correct.

\section{Group Imbedded Figures Test (GEFT)}

GEFT is the adaptation of the original test (EFT) and it is found to be appropriate for group testing. The major difference between this test and the original one (EFT) is that it has the advantage of obtaining scores for many individuals in 20 minutes. The participants were provided with a test consisting of 3 sections and a separate section including 8 simple standard items. The first section encompasses very simple items, and it is for practice. The second and the third sections each contain 9 complex figures. The time limitation is taken to consideration. Subjects should locate simple figures in the complex ones after observing the simple standard items for a few minutes. The first section should be completed after 2 minutes. Five minutes are allocated to the second and the third sections. They should sort the simple items out from complex ones through darkening the outer lines.

\section{Procedure}

The tests were administered in three sessions. In a separate session the students were provided with the GEFT test. They were given 5 minutes to complete the second section and 5 minutes to complete the third section. To divide the students into two groups of high and low fieldindependent ones, the mean and standard deviation for each cognitive style were calculated. Afterwards, 1/4 standard deviations were added to and subtracted from respective means. Accordingly, the researcher could represent the mid-group and mark the boundaries for lower and upper groups. In sum, the groups were identified in the following way:

$$
\begin{aligned}
& \text { Mean }+1 / 4 \text { SD and above }=\text { FI } \\
& \text { Mean }-1 / 4 \text { SD and below }=\text { FD }
\end{aligned}
$$

Initially, the 2000 word level was administered. Afterwards, the productive version of the test was used. After five weeks interval, the passive version was provided. To compute the participants' active and passive vocabulary, the procedure employed by Laufer (1998) was implemented. The following formula was used to measure learners' passive vocabulary.

\section{Passive vocabulary level}

$\{(2000$ passive score* 2$)+3000$ passive score + Academic vocabulary score +5000 passive score $+[(3000$ passive score +5000 score $) / 2]+[5000$ passive score +10000 passive score $)$ $/ 2 * 4]+10000$ passive score $\} / 330 * 10000$ 
The following formula was employed to estimate students' knowledge of active vocabulary.

Active vocabulary level

$\{(2000$ active score $* 2)+3000$ active score +5000 active score + University word List score

$+[(3000$ active score +5000 active score $) / 2]+[(5000$ active score +10000 active score $)$

$/ 2 * 4]+10000$ active score $\} / 198 * 10000$

The raw scores obtained from the questionnaire as well as the passive and productive vocabulary levels were fed into the computer utilizing the SPSS program. Afterwards, the scores for each part were computed and codes were assigned to FD/FI groups.

\section{Results}

\section{Research Question 1}

Is there any significant difference between field-dependents and field-independents in their passive knowledge of vocabulary?

The descriptive statistics for the participants' passive vocabulary levels are displayed in Table 1.

Table 1: Field-Dependent /Independent Participants (Passive Knowledge of Vocabulary)

\begin{tabular}{lccccc}
\hline Cognitive Style & Minimum & Maximum & Mean & S.D & Variance \\
\hline Field-dependents & 2772 & 3984 & 3475.84 & 368.22 & 135591.2 \\
Field-independents & 3212 & 6363 & 4765.21 & 709.15 & 502905.0 \\
\hline
\end{tabular}

As it is evident, field-independent learners enjoyed a higher mean score (4765.21) considering their passive vocabulary levels compared to their field-dependent counterparts who gained a lower mean score (3475.84).

Table 2: Independent Samples t-test Between Field-Dependents and FieldIndependents Regarding their Passive Vocabulary Knowledge

\begin{tabular}{lcccc}
\hline $\begin{array}{l}\text { Mean } \\
\text { difference }\end{array}$ & F & t-value & df & Sig (2-tailed) \\
\hline 1289.36 & 7.85 & 9.06 & 52.02 & .000 \\
\hline
\end{tabular}


The result of the independent samples t-test between FD/FI participants considering their passive vocabulary levels with $(\mathrm{df}=52.02)$ and $(\mathrm{P}=.000)$ is reported to be significant. It shows that field-independent learners outperformed the field-dependent ones regarding their passive vocabulary levels. Such a priority is shown in Figure 1 graphically.

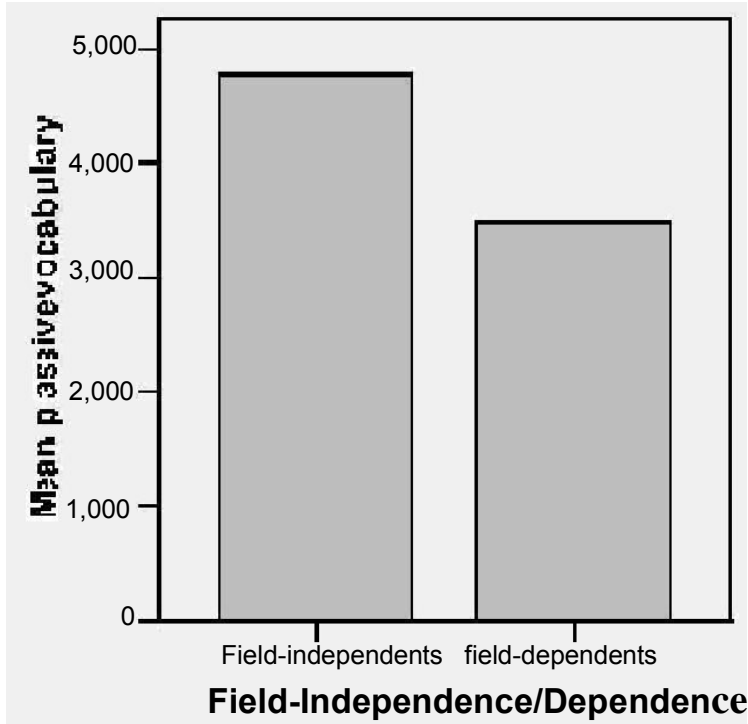

Figure 1: Field-dependent/independents' passive vocabulary levels

\section{Research Question 2}

Is there any significant difference between field-dependents and field-independents in their active knowledge of vocabulary?

The descriptive statistics for the participants' active vocabulary levels are displayed in Table 3.

Table 3: Field-Dependent/Independent Participants (Active Knowledge of Vocabulary)

\begin{tabular}{lccccc}
$\begin{array}{l}\text { Cognitive } \\
\text { Style }\end{array}$ & Minimum & Maximum & Mean & S.D & Variance \\
\hline $\begin{array}{l}\text { Field- } \\
\text { Dependents }\end{array}$ & 1035 & 3510 & 2261.48 & 640.88 & 410731.3 \\
$\begin{array}{l}\text { Field- } \\
\text { Independents }\end{array}$ & 1313 & 4469 & 2866.38 & 821.57 & 674986 \\
\hline
\end{tabular}

The results in table 3 reveal the fact that field-independent participants gained a higher mean score (2866.38) compared with field-dependent ones with the mean score of (2261.48). 
Table 4: Independent Samples t-test Between Field-Dependent and Field-Independent

Participants Regarding their Active Vocabulary Knowledge

\begin{tabular}{ccccc}
\hline $\begin{array}{c}\text { Mean } \\
\text { Difference }\end{array}$ & F & t-value & d.f & sig (2-tailed) \\
\hline 604.902 & 2.61 & 3.05 & .57 & .003 \\
\hline
\end{tabular}

Similar analyses were carried out considering the scores obtained for the two groups of FD/FI learners regarding their active vocabulary levels. The result of the independent samples t-test with $(\mathrm{df}=.57)$ and $(\mathrm{P}=.003)$ is reported to be significant which is interpreted as the sign of the priority of field-independent participants regarding their active vocabulary performance. Such a priority is represented graphically in Figure 2.

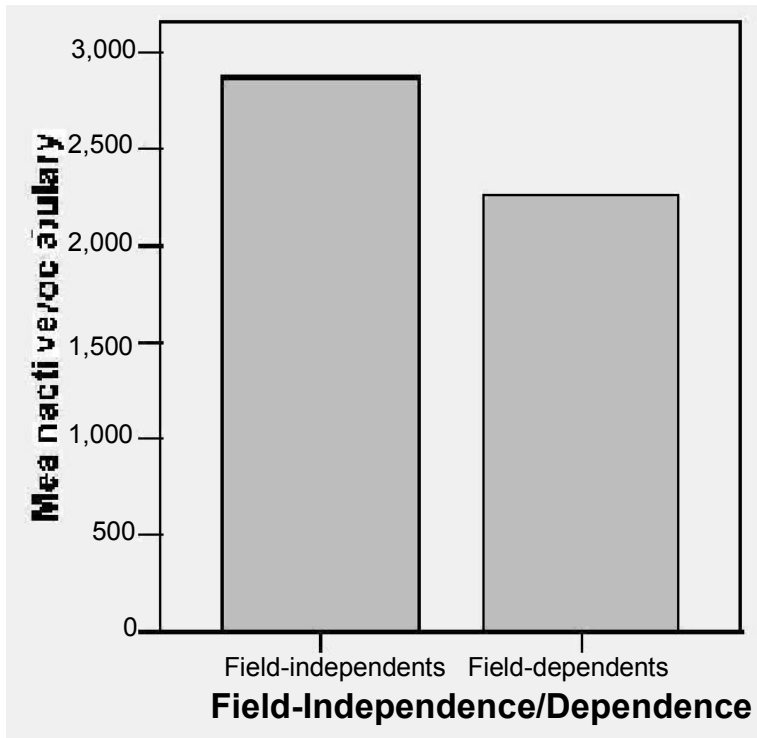

Figure 2: Field-dependent/independents' active vocabulary levels

\section{Pedagogical Implications and Suggestions for Further Research}

Perhaps the most significant application of this survey is pertinent to the domain of language teaching. The results of this study could be of benefit to all language teachers, test developers, and syllabus designers. As people with different cognitive styles might have different performance outcomes in language learning, evaluating students with regard to these learning characteristics, and differentiating between them in reference to their lexical knowledge, would lead to a more reliable assessment of their lexical performance, and consequently could result in more effective language teaching strategies and learning. 
Pragmatically, understanding the predisposition of language learners in terms of cognitive styles could provide a basis for materials development to adapt performances, altering natural tendencies.

In other words, based on such findings, strategies could be developed to adjust teaching circumstances so as to appropriately respond to the students' needs. These strategies can reinforce learning efficiency. The role of a proper syllabus in learning is something of paramount importance. In appropriate situations, when it is possible to take such cognitive styles into consideration, language teachers can observe a higher degree of enthusiasm towards the acquisition of different facets of language.

Future work on this project, to be reported later, may encompass study of the probable interaction of the learners' FD/FI cognitive style and the teachers' cognitive style as a factor influencing learners' achievement as well as the relationship between the learners' cognitive style of field-dependence/independence and the deductive/inductive methods of teaching grammar.

\section{Discussion and Conclusion}

The results show clear preferences for specific categories. Field-independent language learners gained higher marks compared to their field-dependent counterparts in both fields of passive and productive vocabulary testing. The results of the study could be justified by carefully scrutinizing the content and format of the Vocabulary Levels Tests. In dealing with the test, the task of the student is not to process everything that was presented, but rather to scan each item selectively for certain information with the purpose of matching the three intended words on the right with their pairs on the left. This is true especially in case of passive section which demands high analytical ability. Technically speaking, the test epitomizes a bottom-up approach to language performance in which the test-taker has to act like a scientist with a magnifying glass or microscope examining all the minute details of the task provided by the test. In other words, the higher performance of field-independent learners may be due to the fact that they were expected to find important information in a field of potentially distracting information and not to look for global or general meanings. The results obtained in favor of field-independent learners in the present study stand in conformity with the findings reported by Lu and Suen (1995) and Yamini and Rahnama (2008) who found 
similar results regarding the field-independent participants of their study. To sum up, this study is presented in the belief that knowledge and awareness of learning styles in accordance with students' abilities in a specific realm of language like lexical domain will allow the development of natural strengths and predispositions that suggest areas for further growth and help motivation. For teachers, such awareness will also have beneficial effects, aiding in methodological choices, helping in the recognition of individual differences, and improving teacher-student understanding.

The ultimate goal of this research is to provide teachers with a more vivid perspective of the psycholinguistic, pedagogical, and practical facets of language learning that enable them to assist the students to identify their own cognitive styles and to nurture and, where necessary and feasible, refine their own current repertoire of learning strategies in the way of fostering their lexical knowledge.

\section{References}

Adamopoulos, R. (2004). Personality and second language acquisition. ENGL. 539. Second Language Acquisition. Retrieved from http://salisbury. edu/ acu/ portfolio samples.

Anastasi, A., \& Urbina, S. (2005). Psychological testing. Prentice Hall of India.

Brown. H, D. (2007). Principles of language learning and teaching. Pearson Education, Inc.

Cook, V. (1991). Second language learning and language teaching. New York: Routledge Chapman and Hall.

Cruickshank, D. R., \& Jenkins, D. B., \& Metcalf, K. K. (2006). The act of teaching. McGraw-Hill Companies, Inc.

Golkar, M., \& Yamini, M. (2007). Vocabulary proficiency and reading comprehension. The Reading Matrix, 7(3), 88-107.

Hatch, E., \& Brown, C. (1995). Semantics, and language education. Cambridge University Press.

Laufer, B., \& Nation, P. (1999). A vocabulary-size test of controlled productive ability. Language Testing Journal, 16 (1).

Laufer, B., \& Paribakht, S.T. (1998). The relationship between passive and active vocabularies. Effects of language learning contexts. Language Learning Journal, 48(3), 365-391.

Nation, P. (1993). Measuring readiness for simplified material: A test of the first 1,000 words of English. In simplification: Theory and application M.L. Ticko (ed.). RELC Anthology Series, 31, 193-203.

Schmitt, N., Schmitt, D., \& Claphan, C. (2001). Developing and exploring the behavior of two new versions of the vocabulary levels test. Language Testing, 18(1), 55-58.

Schoonen, R., \& Verhallen, M. (2008). The assessment of deep word knowledge in young first and second language learners. Language Testing Journal, 25(2), 211-236.

Shaw, H., \& Date, P. (1986). Handbook of English. Mc Graw-Hill, Inc.

Srivastava, V.P. (1997). Cognitive style in educational research. Anmol Publications. New Delhi-1100002, India.

Wesche, M., \& Paribakht, T. S. (2010). Lexical inferencing in a first or second language. Cross-linguistic dimensions. British Library Cataloguing in Publication Data.

William, M., \& Burden, L. R. (1997). Psychology for Language Teachers. Cambridge University Press.

Yamini, M., \& Rahnama , M. (2008). Relation between field dependence/independence, ambiguity tolerance /intolerance and reading comprehension regarding global and local items. Journal of Humanities and Social Sciences, 2(2), 63-72. 